\title{
Case report of an isolated fracture of the anatomic neck of the scapula
}

\author{
Drew P Kelly, Zachary V Roberts \\ The University of Oklahoma Health Sciences Center, Department of Orthopedic Surgery \& Rehabilitation, Oklahoma City, \\ United States
}

Received: December 15, 2015

Accepted: February 10, 2016

Online Published: February 24, 2016

DOI: $10.5430 /$ css.v2n2p23

URL: http://dx.doi.org/10.5430/css.v2n2p23

\begin{abstract}
Isolated fractures of the anatomic neck of the scapula are extremely rare. To our knowledge, seven such fractures have been previously reported in the literature with radiographic documentation. We describe another such case and review the anatomy contributing to deformity in this injury pattern. As with previous cases of this fracture pattern, the plane of the fracture divided the scapular body from the glenoid fossa, with a short spike of the lateral border of the scapular body attached to the glenoid fragment. The glenoid fragment demonstrates a unique pattern of inferior displacement and valgus alignment due to the deforming forces produced by the anatomic structures spanning the fracture. This unstable fracture was fixed through a modified Judet posterior approach and yielded excellent results.
\end{abstract}

Key Words: Scapula fracture, Scapula neck fracture, Anatomic neck fracture, Glenoid fracture, Suspensory system, Modified Judet approach

\section{INTRODUCTION}

Scapula fractures account for $1 \%$ of all fractures, and isolated fractures of the anatomic neck represent $1 \%$ or less of all scapula fractures, making these injuries extremely rare. ${ }^{[1]}$ In designing the recently updated AO Foundation and Orthopaedic Trauma Association (AO/OTA) scapula fracture classification system, Jaeger et al. ${ }^{[1]}$ identified one isolated anatomic neck fracture among 120 consecutive scapula fractures documented with CT scans and conventional radiographs obtained from 2 centers in Europe and North America. They designated this fracture 14-F0, defined as a "fracture of the articular segment, not through the glenoid fossa, but resulting in the fossa being detached from any part of the scapula body". Bartonicek et al. described two such fractures in 2013 and identified a total of four others in the literature with radiographic documentation, ${ }^{[2]}$ followed by a related report in 2014 in which they identified one additional anatomic neck fracture. ${ }^{[3]}$ The purpose of this report is to describe another such case and review the anatomy contributing to deformity in this injury pattern.

\section{CASE PRESEntation}

Our patient was a 26-year-old female who was involved in a motor vehicle collision during January 2014 in which she sustained an isolated, closed injury to her left (non-dominant) shoulder, resulting in a displaced fracture of the anatomic neck of her scapula. Her shoulder was immobilized with a sling, and she was referred to our trauma center by a community surgeon for a higher level of care several days later. Physical exam demonstrated a major sulcus sign at rest con-

\footnotetext{
* Correspondence: Drew P Kelly; Email: drew-kelly@ouhsc.edu; Address: The University of Oklahoma Health Sciences Center, Department of Orthopedic Surgery \& Rehabilitation, Williams 1380, 920 Stanton L Young Blvd, Oklahoma City, 73104, United States.
} 
sistent with inferior displacement of the humeral head. Radiographs demonstrated a fracture line separating the scapular body from the glenoid, with a portion of the lateral border of the scapular body attached to the glenoid fragment (see Figure 1). The fracture line extended from the coracoglenoid notch superiorly to the lateral border of the scapular body $3 \mathrm{~cm}$ distal to the inferior pole of the glenoid. The glenoid piece was displaced $2 \mathrm{~cm}$ inferiorly with widening of the subacromial space such that the humeral head was situated inferior to the level of coracoid. There was widening of the inferior fracture site resulting in 15-20 degrees of valgus alignment between the scapular body and the glenoid spike.
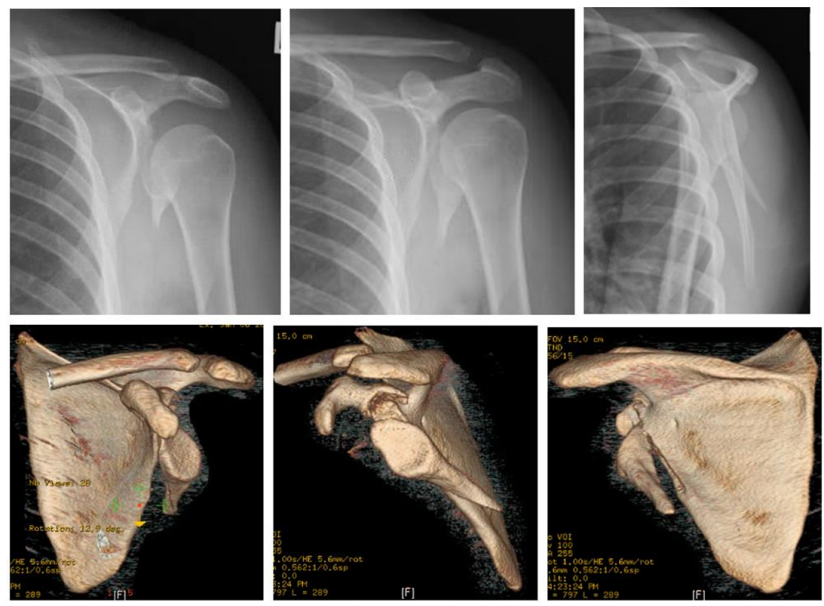

Figure 1. Injury radiographs

Plain films (internal rotation, external rotation, and scapula $Y$ ) and $3 D$ reconstructed CT images (anterior, lateral, and posterior) of the patient's scapula at time of injury demonstrate typical displacement for an anatomic scapular neck fracture: inferior displacement, valgus rotation of the glenoid fragment in the coronal plane resulting in an increased glenopolar angle, and forward rotation of the superior pole of the glenoid in the sagittal plane.
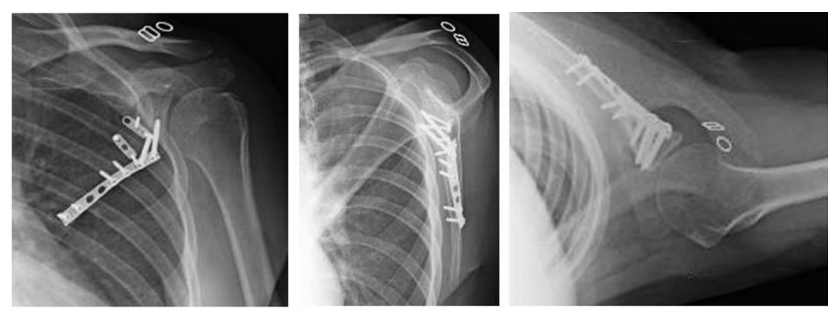

Figure 2. Three-month postoperative films

$A P$, scapula $Y$, and axillary lateral views of the patient's shoulder taken three months after surgery demonstrate direct healing in anatomic position.

Open reduction internal fixation was performed via modified Judet posterior approach on the ninth day after her motor vehicle collision. The fracture was cleaned and reduced anatomically, and two $2.0 \mathrm{~mm}$ plates and several $2.4 \mathrm{~mm}$ screws were used for provisional fixation across the fracture site followed by a lateral buttress plate with multiple lag screws through the plate. She was admitted for pain control and discharged on postoperative day two. She wore a sling for two weeks. She began passive range of motion two weeks after surgery and strengthening exercises six weeks after surgery. Three month films demonstrated direct healing in anatomic position (see Figure 2). Full function of the shoulder was restored.

\section{Discussion}

Most operative scapula fractures involve a transverse fracture line caudal to the scapular spine with the caudal segment displaced laterally, owing to the pull of the infraspinatus, teres major and minor, and latissimus dorsi (Ada and Miller type IIC, revised AO/OTA type 14-A3). ${ }^{[4,5]}$ This is markedly distinct from fractures of the anatomic neck of the scapula.

With fractures of the anatomic neck of the scapula, the fragment attached to the proximal humerus is formed by the glenoid fossa and a portion of the lateral border of the scapular body as described by Bartonicek et al. ${ }^{[2]}$ The fracture runs vertically from the coracoglenoid notch superiorly to a point along the lateral border of the scapular body that is $2 \mathrm{~cm}-4 \mathrm{~cm}$ distal to the inferior pole of the glenoid. Clinically these injuries present with a major sulcus sign consistent with inferior translation of the humeral head, and radiographically the subacromial space is widened with the humeral head positioned inferior to coracoid.

Lambert et al. describe two intimately related and overlapping lateral scapular suspensory systems: an "inner" one (lateral clavicle, acromioclavicular ligament, coracoacromial ligament, coracoid body, coracoclavicular ligaments, and lateral clavicle) and an "outer" one (clavicle, acromioclavicular joint, scapular spine, lateral scapular angle, coracoclavicular ligaments, and clavicle). ${ }^{[6]}$ While none of these structures are damaged in the setting of an anatomic neck fracture, Arts and Louette suggested this injury represents a floating shoulder variant. ${ }^{[7]}$ Unlike a fracture of the surgical neck of the scapula (i.e. medial to the coracoid process), which may be stabilized by an intact clavicle or coracoclavicular ligaments, a fracture of the anatomic neck (i.e. lateral to the coracoid process) will still be relatively unstable even if the other structures of the suspensory ring are intact. The only osseoligamentous structure attaching the humerus to the suspensory system is the coracohumeral ligament, which may provide some limit against inferior excursion of the upper extremity with gravity. The only attachment between the glenoid fragment and the proximal scapula is the inferior transverse ligament of the scapula, which connects the spine 
of the scapula to the posterosuperior glenoid rim and forms the dorsal arch through which the suprascapular neurovascular bundle passes on its way to the infraspinatus fossa. This represents another possible superior tether for the glenoid fragment as well as a putative site of suprascapular neurovascular bundle compression in the setting of this injury which has never been described.

The glenohumeral joint capsule and three distinct glenohumeral ligaments (superior, middle, and inferior) attach medially to the periphery of the labrum, bony rim, and anatomic neck. The inferior glenohumeral ligament, the longest of the three glenohumeral ligaments, extends towards the surgical neck of the scapula but blends into the scapular periosteum within about $10 \mathrm{~mm} .{ }^{[8]}$ Since the fracture line generally extends $2 \mathrm{~cm}-4 \mathrm{~cm}$ distal to the inferior pole of the glenoid with fractures of the anatomic neck of the scapula ${ }^{[2]}$ the capsular attachment is entirely contained along the glenoid fragment. Intraarticular negative pressure created by the intact capsule is responsible for the continued intimate relationship of the humeral head and glenoid despite the pull of gravity on the upper extremity.

In addition to these capsuloligamentous attachments, several muscles span the fracture plane, namely the deltoid, rotator cuff, and long heads of the biceps and triceps brachii. The complete bony lesion at the anatomic neck of the scapula results in an unstable center of rotation for the shoulder, which allows the characteristic rotational deformity of the glenoid fragment in several planes. In the coronal plain, the deltoid overpowers the more inferior muscles and pulls the humerus along with the glenoid fragment into valgus via the capsular attachment. In the sagittal plane, the long head of biceps causes the superior pole of the glenoid to rotate forward, and the long head of triceps acts with gravity to create inferior translation of the glenoid fragment through its attachment to the inferior pole.

This unique injury defies easy radiographic measurements and well-defined operative criteria alike. According to the method described by Anavian et al.,${ }^{[9]}$ the glenopolar angle measured approximately 55 degrees, and the anterior angulation was 20 degrees in the sagittal plane. There was no significant sagittal plane translation or glenoid version deviation. As previous authors have pointed out, this injury is singularly exceptional in that it results in valgus alignment of the glenoid fragment and an increased glenopolar angle. ${ }^{[2]}$ Explicit surgical indications in the literature that might apply to this injury include $>10 \mathrm{~mm}-20 \mathrm{~mm}$ medial/lateral displacement, $>25-45$ degrees of angular deformity on a scapular-Y view, double disruptions of the superior shoulder suspensory complex with both displaced $>10 \mathrm{~mm}$, glenopolar angle
$<22$ degrees, and open fractures. ${ }^{[5]}$ This fracture meets none of those criteria but nonetheless represents an unstable pattern unlikely to heal predictably without operative stabilization due to the deforming forces described above. We agree with the previous few authors who have published reports on these rare injuries that open reduction internal fixation is warranted and reliably produces satisfactory clinical results.

With the exception of bony Bankart lesions, which may be addressed arthroscopically or through an open deltopectoral approach ${ }^{[10]}$ a posterior approach is needed for operative stabilization of most scapula fractures, including fractures of the anatomic neck. While a variety of posterior approaches to the shoulder have been described, we believe that the modified Judet approach has several advantages over other exposures for this unique injury. The classic Judet approach involves making a curvilinear incision overlying the scapular spine and medial scapular border, elevating the infraspinatus from its fossa, and reflecting the muscle from medial to lateral on its neurovascular pedicle. ${ }^{[11]}$ The posterior deltoid can be released from its origin along the scapular spine ${ }^{[12]}$ or even split to provide further access to the superior and lateral part of the scapula. ${ }^{[13]}$ A modified Judet approach utilizes a similar incision to allow access to the internervous interval between the infraspinatus and teres minor without reflection of the infraspinatus, which minimizes soft tissue stripping and risk of injury to the neurovascular pedicle, while still providing adequate access to the thick bone of the lateral border of the scapula where the best bone stock for fixation is located. ${ }^{[14]}$ A minimally invasive posterior approach has been described which uses multiple small incisions to gain access to the same internervous interval along the thick borders of the scapula, ${ }^{[15]}$ but limited skin incisions may prove challenging for surgeons who rarely operate on the posterior shoulder or in obese patients in whom bony landmarks are obscured. The so-called "two-portal" approach utilizes the same internervous interval but also mobilizes the infraspinatus caudally to provide access to superior border of the scapula between the infraspinatus and supraspinatus, ${ }^{[16]}$ with the added risk of injury to the suprascapular neurovascular bundle. Partial or complete infraspinatus tenotomy has been described as another extension of the modified Judet approach, ${ }^{[13]}$ which avoids risks associated with soft tissue stripping in the classic Judet approach but carries the obvious drawback of potential tendon healing complications and risk of rotator cuff dysfunction. Triceps tenotomy has been shown to improve visualization of the inferior glenoid as well as allow palpation of the anterior glenoid with the Judet approach in cadaveric specimens. ${ }^{[17]}$ Authors of the previously limited case reports dealing with surgical treatment of 
fractures of the scapular anatomic neck were able to achieve anatomic reduction and adequate fixation in all cases without performing any tenotomy, ${ }^{[2]}$ as in this case.

In conclusion, fractures of the anatomic neck of the scapula are extremely rare injuries that demonstrate a unique pattern of inferior displacement and valgus alignment of the glenoid fragment due to the deforming forces produced by the anatomic structures spanning the fracture. Our case rep- resents the ninth one reported in the literature with accompanying radiographs. These are unstable injuries that warrant operative stabilization. Open reduction internal fixation via modified Judet approach can produce excellent results as in this case.

\section{CONFlicts OF InTEREST Disclosure}

The authors declare they have no conflict of interest.

\section{REFERENCES}

[1] Jaeger M, Lambert S, Südkamp NP, et al. The AO Foundation and Orthopaedic Trauma Association (AO/OTA) scapula fracture classification system: focus on glenoid fossa involvement. J Shoulder Elbow Surg. 2013 Apr; 22(4): 512-20. PMid: 23021902. http: //dx.doi.org/10.1016/j.jse.2012.08.003

[2] Bartoníček J, Tuček M, Frič V, et al. Fractures of the scapular neck: diagnosis, classifications and treatment. Int Orthop. 2014 Oct; 38(10): 2163-73. PMid: 24996398. http://dx.doi.org/10.1007/s00 264-014-2434-7

[3] Bartoníček J, Tuček M, Frič V, et al. Fractures of the scapular neck: diagnosis, classifications and treatment. Int Orthop. 2014 Oct; 38(10): 2163-73.

[4] Ada JR, Miller ME. Scapular fractures. Analysis of 113 cases. Clin Orthop Relat Res. 1991 Aug; 269(269): 174-80. PMid: 1864036.

[5] Cole PA, Gauger EM, Herrera DA, et al. Radiographic follow-up of 84 operatively treated scapula neck and body fractures. Injury. 2012 Mar; 43(3): 327-33. PMid: 22036452. http://dx.doi.org/10. 1016/j . injury. 2011.09.029

[6] Lambert S, Kellam JF, Jaeger M, et al. Focussed classification of scapula fractures: failure of the lateral scapula suspension system. Injury. 2013 Nov; 44(11): 1507-13. PMid: 23570705. http: //dx.doi.org/10.1016/j.injury. 2013.03.001

[7] Arts V, Louette L. Scapular neck fractures; an update of the concept of floating shoulder. Injury. 1999 Mar; 30(2): 146-8. http: //dx.doi.org/10.1016/S0020-1383(98)00231-9

[8] McMahon PJ, Dettling J, Sandusky MD, et al. The anterior band of the inferior glenohumeral ligament. Assessment of its permanent deformation and the anatomy of its glenoid attachment. J Bone Joint Surg Br. 1999 May; 81(3): 406-13. PMid: 10872356. http://dx.doi.org/10.1302/0301-620X.81B3.9153

[9] Anavian J, Conflitti JM, Khanna G, et al. A reliable radiographic measurement technique for extra-articular scapular fractures. Clin
Orthop Relat Res. 2011 Dec; 469(12): 3371-8. PMid: 21360211. http://dx.doi.org/10.1007/s11999-011-1820-3

[10] Chen L, Xu Z, Peng J, et al. Effectiveness and safety of arthroscopic versus open Bankart repair for recurrent anterior shoulder dislocation: a meta-analysis of clinical trial data. Arch Orthop Trauma Surg. 2015 Apr; 135(4): 529-38. PMid: 25743570. http://dx.doi.org/10.1007/s00402-015-2175-0

[11] Judet R. Surgical Treatment of Scapula Fractures. Acta Orthop Belg. 1964; 30: 673-8. PMid: 14291980.

[12] Salassa TE, Hill BW, Cole PA. Quantitative comparison of exposure for the posterior Judet approach to the scapula with and without deltoid takedown. J Shoulder Elbow Surg. 2014 Nov; 23(11): 1747-52. PMid: 24862248. http://dx.doi.org/10.1016/j.jse. 2014 . 02.025

[13] Wirth MA, Butters KP, Rockwood CA. The posterior deltoid-splitting approach to the shoulder. Clin Orthop. 1993 Nov; (296): 92-98. http://dx.doi.org/10.1097/00003086-199311000-00017

[14] Jones CB, Cornelius JP, Sietsema DL, et al. Modified Judet approach and minifragment fixation of scapular body and glenoid neck fractures. J Orthop Trauma. 2009 Sep; 23(8): 558-64. PMid: 19704270. http://dx.doi.org/10.1097/BOT . Ob013e3181a18216

[15] Gauger EM, Cole PA. Surgical technique: a minimally invasive approach to scapula neck and body fractures. Clin Orthop Relat Res. 2011 Dec; 469(12): 3390-9. PMid: 21761253. http: //dx.doi.org/10.1007/s11999-011-1970-3

[16] Pizanis A, Tosounidis G, Braun C, et al. The posterior two-portal approach for reconstruction of scapula fractures: results of 39 patients. Injury. 2013 Nov; 44(11): 1630-5. PMid: 23972388. http://dx.doi.org/10.1016/j.injury . 2013.07.020

[17] Harmer LS, Phelps KD, Crickard CV, et al. A Comparison of Exposure between the Classic and Modified Judet Approach to the Scapula. J Orthop Trauma. 2015 Nov 4 [Epub ahead of print]. http://dx.doi.org/10.1097/BOT.0000000000000486 